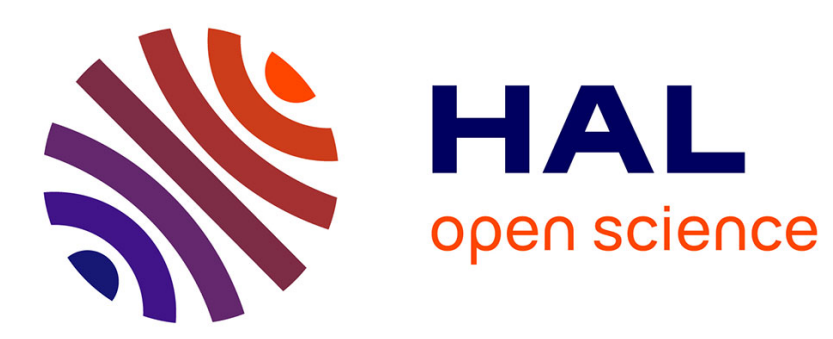

\title{
Modeling the structural behavior of reinforced concrete walls under ISO fire exposure
}

\author{
Mohsen Roosefid, Marie Helene Bonhomme, Pierre Pimienta
}

\section{To cite this version:}

Mohsen Roosefid, Marie Helene Bonhomme, Pierre Pimienta. Modeling the structural behavior of reinforced concrete walls under ISO fire exposure. 11th International Conference on Structures in Fire, SiF 2020, Nov 2020, online, Australia. pp.1-9, 10.14264/025d425 . hal-03220003

\section{HAL Id: hal-03220003 \\ https://hal.science/hal-03220003}

Submitted on 6 May 2021

HAL is a multi-disciplinary open access archive for the deposit and dissemination of scientific research documents, whether they are published or not. The documents may come from teaching and research institutions in France or abroad, or from public or private research centers.
L'archive ouverte pluridisciplinaire HAL, est destinée au dépôt et à la diffusion de documents scientifiques de niveau recherche, publiés ou non, émanant des établissements d'enseignement et de recherche français ou étrangers, des laboratoires publics ou privés.

\section{다)(1) $(5$}

Distributed under a Creative Commons Attribution - NonCommercial| 4.0 International 


\title{
MODELING THE STRUCTURAL BEHAVIOR OF REINFORCED CONCRETE WALLS UNDER ISO FIRE EXPOSURE
}

\author{
Mohsen Roosefid ${ }^{1}$, Marie Helene Bonhomme ${ }^{2}$, Pierre Pimienta ${ }^{3}$
}

\begin{abstract}
Despite a century of experience and a great deal of effort, considering the risk of thermal instability of concrete when exposed to fire is still in many cases a very difficult task as it includes many uncertainties in real practice. Moreover, there is lack of validated numerical models for predicting realistic behaviour of concrete structural elements under fire exposure.

In the framework of the international benchmark "Vulcain tests on 3 Walls", three full scale ISO fire tests on a reinforced concrete wall, simultaneously subjected to a constant uniaxial compressive load, were conducted in CSTB in Paris, France. The duration of these tests exceeded 120 minutes. In order to assess the capability of available finite elements (FE) models to represent reinforced concrete structural behaviour under fire exposure, IRSN, within the scope of the Vulcain benchmark, developed a concrete model with help of Mazars isotropic continuum damage mechanical model [1] ran with the CAST3M software [2]. Also, the numerical simulation of three full scale ISO fire tests of Vulcain was carried out with the help of a FE model that takes into account the values of the concrete thermomechanical parameters previously identified. The numerical model is composed of two different parts, one for heat transfer analysis and the other one for structural analysis based on a 3D FE model including concrete and reinforcing steel meshes. It is illustrated through this numerical investigation that the proposed model can predict the thermomechanical behaviour of reinforced concrete walls under fire exposure.
\end{abstract}

Keywords: Concrete structures; finite element modelling; damage model; reinforced concrete walls; transient strain

\section{INTRODUCTION}

Fire is a major risk for the safety of the nuclear facilities that can act on the building structures as an external and internal aggression. Reinforced concrete structures are widely used in the nuclear facilities, in which fire can induce severe damages (cracks, fissures and spalling etc.), and therefore the impact of fire needs to be considered carefully through a combined structural and fire engineering assessment. The reinforced concrete bearing walls in the nuclear facilities have to be designed for minimum two hours of fire resistance according to the regulations of the French "Autorité de Sûreté Nucléaire" (Nuclear Safety Authority), especially due to their effective role in the fire sectorization. Moreover, the nuclear requirements e.g. the confinement of radioactivity impose additional constraints on the fire safety provisions in order to limit the concrete cracking or spalling risk. However, more evidence is still necessary to confirm such fire

\footnotetext{
${ }^{1} \mathrm{PhD}$, Civil Engineer, Nuclear Safety Division, Equipement ans Struture Assessment Departement, Civil Engineering Assessment Section, IRSN e-mail: mohsen.roosefid $@$ irsn.fr

${ }^{2}$ Head of Section, Nuclear Safety Division, Equipement ans Struture Assessment Departement, Civil Engineering Assessment Section, IRSN e-mail: marie-helene.bonhomme@irsn.fr

${ }^{3}$ Vice head of Division, Fire Studies and Tests Division, Safety, Structures and Fire Direction, CSTB, Université Paris Est e-mail: pierre.pimienta@cstb.fr, ORCID: https://orcid.org/0000-0002-9087-5657
} 
performance of concrete structures because there are limited data available, especially regarding to the degradation of concrete structures due to ageing related phenomena.

In order to gain a deeper understanding, three full-scale reinforced concrete wall tests were carried out in CSTB in the framework of the International benchmark "Vulcain tests on 3 Walls". The aim of this work is to provide the possibility to check the validity of the advanced modelling which is more and more widely applied to investigate such type of structure system in fire safety engineering. In consequence, a numerical model developed on the basis of a finite element (FE) computer code has been applied to these tests. The calculated results were then compared to experimental ones, from which one can get an accurate idea about the precision of the numerical model.

\section{VULCAIN FIRE TESTS}

Three full-scale reinforced concrete walls of section $1.2 \mathrm{~m}$ width, $0.2 \mathrm{~m}$ thick and $3.0 \mathrm{~m}$ height were exposed on one side to ISO 834-1 fire with 3 different levels of uniaxial mechanical loading $(0,100$ and $1100 \mathrm{kN})$. Each wall involved an ordinary concrete ( $\mathrm{fc} 28$ days $=32 \mathrm{MPa}$ ) and was reinforced by a steel mesh (rebar $\emptyset 5.5 \mathrm{~mm}$, mesh $11.9 \times 11.9 \mathrm{~mm}^{2}$ ) positioned at $5 \mathrm{~cm}$ from the shuttered surface. All the walls were tested at the age of 2 years. The wall specimens were loaded before the fire test and then the load was maintained constant throughout the fire test. The boundary conditions at the top and the bottom of the walls were pivot connections centred on the thickness allowing only rotation along the length horizontal axis. No spalling was observed on any of the 3 walls [8].

\section{NUMERICAL INVESTIGATION OF THE FIRE TESTS}

Within the scope of the Vulcain benchmark, it is intended to conduct a numerical study on the basis of advanced calculation models validated against the fire tests in order to develop appropriate design guidelines on the stability of concrete walls when exposed to fire and external mechanical loading [8]. The three fire tests described above constitute then ideal experimental evidence to check the validity of numerical design tools. In consequence, Vulcain fire tests have been subjected to a specific numerical investigation with help of a 3D structural FE model. The numerical model is composed of two different parts, one for heat transfer analysis and another one for mechanical analysis. In the mechanical analysis, the modelling of fire behaviour of concrete involves the use of damage models that have the ability to compute time to failure. For this purpose, Mazars' damage model was used in which an elasticity model and damage theory are coupled. As far as reinforcing steel mesh is concerned, its behaviour was modelled as elastic-perfectly plastic according to EN 1992-1-2 [10].

\subsection{Modelling}

Experiments have brought to light the complex mechanical behaviour of concrete structures in fire conditions. Few models describe this behaviour and their implementation in a finite elements method is scarce

The present analysis is based on elasticity coupled with Mazars' damage model. In this regard, a number of comments need to be made. Firstly, a suitable model should respect the non-symmetry of behaviour between tension and compression. Secondly, the concrete presents a strong heterogeneity characterised by the presence of many defects (pores, micro-cracks...). Damage mechanics is particularly suitable to describe materials containing micro defects such as porosity, cavities, cracks that alter the rigidity of the macro material. Moreover damages have been evidenced in the fire tests and should be taken into account. In consequence, we decided to model the concrete behaviour with a damage mechanics model.

Additionally, one important choice is that the model must allow the finite element calculation of concrete structures in fire. Moreover, its final industrial use imposes robustness and easy implementing. In general the finer the description of the material behaviour, the bigger the problems of numerical convergence are in concrete structures simulation, thus in practice limiting utility of the modelling. All these considerations 
brought us to model the concrete behaviour thanks to an elastic damage mechanics model (Mazars model), which is implemented in CAST3M finite element code.

\subsubsection{Mazars's elastic damageable model}

The Mazars's constitutive model is an elastic model that includes damage theory that is based on the concept of effective stress [9]. The concrete is supposed to behave elastically and to remain isotropic, and it is assumed that only the elastic properties of the concrete are affected by damage. The coupling of elasticity and damage processes is achieved by substituting the nominal stress tensor, $\sigma$, by the effective stress tensor, $\tilde{\sigma}$, in accordance with the strain equivalence principle. This leads to:

$\sigma=(1-D) . \widetilde{\sigma}$

where $D$ is the damage parameter.

The damage parameter $D$ is defined as a combination of two damaging modes defined by $D_{t}$ and $D_{c}$, for tensile and compressive states of stress, respectively, and ranges between 0 and $1(0<D<1)$.

When $D$ is 0 , the concrete is undamaged, whereas a value close to 1 indicates a rupture of the concrete.

The damage is controlled by the equivalent deformation, $\tilde{\varepsilon}$, who takes into account only the positive value of the principal strain:

$\tilde{\varepsilon}=\sqrt{\left\langle\varepsilon_{1}\right\rangle_{+}^{2}+\left\langle\varepsilon_{2}\right\rangle_{+}^{2}+\left\langle\varepsilon_{3}\right\rangle_{+}^{2}}$

where $\left\langle\varepsilon_{1}\right\rangle_{+}$are defined as follows:

$\left\langle\varepsilon_{1}\right\rangle_{+}=\varepsilon_{i} \quad \varepsilon_{i} \geq 0$

$\left\langle\varepsilon_{1}\right\rangle_{+}=0 \quad \varepsilon_{i}<0$

According to the damage model, damage occurs when the state of tension in the material reaches a certain threshold $K$. The damage occurrence criterion is expressed:

$f(\varepsilon, D)=\tilde{\varepsilon}-K(D)=0$

with $K(D)=\varepsilon_{D 0}$ if $D=0$ in which $\varepsilon_{D 0}$ is the strain threshold.

The parameters $D_{t}$ and $D_{c}$ are explicitly related to the equivalent strain, $\tilde{\varepsilon}$, and the strain threshold, $\varepsilon_{D 0}$. The associated equations are, respectively, for tension and compression:

$D_{t}=1-\frac{\varepsilon_{D 0}\left(1-A_{t}\right)}{\tilde{\varepsilon}}-\frac{A_{t}}{\exp \left[B_{t}\left(\tilde{\varepsilon}_{M}-\varepsilon_{D 0}\right)\right]}$

$D_{c}=1-\frac{\varepsilon_{D 0}\left(1-A_{C}\right)}{\tilde{\varepsilon}}-\frac{A_{C}}{\exp \left[B_{C}\left(\tilde{\varepsilon}_{M}-\varepsilon_{D 0}\right)\right]}$

The parameters $A_{t}, A_{c}, B_{t}$, and $B_{c}$, describe the shape of the stress-strain curve and can be identified on the basis of the uniaxial monotonic loading in tension and compression tests.

\subsubsection{Parameters calibration}

The identification of the evolution of the damage parameters of the Mazars model has been performed on the basis of tests results carried out within the framework of Mindeguia's thesis [3]. The procedure of identification of the Mazars' model parameters will not be reported in the present paper.

Figure 1 presents the evolution of the concrete compressive damage parameters of the Mazars model. 


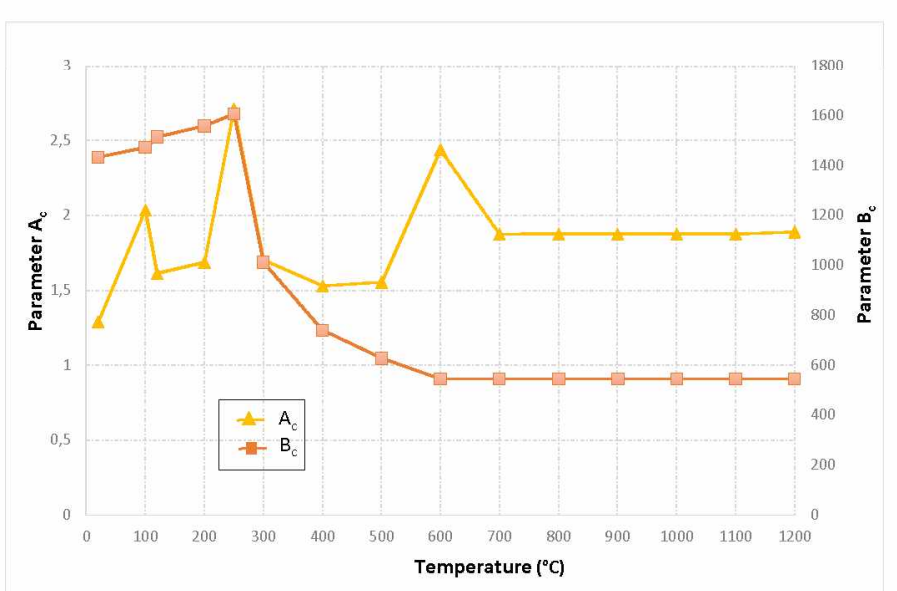

Figure 1. Parameters $A_{c}$ et $B_{c}$ as a function of temperature

In tension, the concrete behaviour is considered elastic up to the peak. Thus, the damage threshold in equation (5) was expressed in strain at peak, i.e., $\left(\varepsilon_{D 0}=\frac{f_{t}}{E}\right)$ where $E$ is the Young modulus of elasticity, and $f_{\mathrm{t}}$ the tensile strain at peak.

The post-peak in tension is calibrated using the energetic-regularization technique based on the so-called Hillerborg method [5] in which it was demonstrated that damage is typically diffuse for reinforced concrete structures. The Mazars' model parameter $B_{t}$, driving the shape of the strain softening, can be written as follows:

$B_{t}=\frac{h f_{t}}{G_{f}}$

where $G_{f}$ is the fracture energy and $h$ corresponds to the size of the finite element.

In this framework, identification of numerical values of the constitutive equations in tension has been performed with the Hillerborg approach. In a second approach, the calculations ran to identify the parameter values were also performed assuming a non-local application of the Mazars model in order to avoid mesh dependency at the structural level.

The Mazars' model parameter $A_{t}$ is taken constant and equal to 0.8 and -10 for nonlocal technique and Hillerborg approach, respectively. Moreover, the use of the non-local formulation of Mazars model requires the introduction of a characteristic length which is estimated at three times the maximum aggregate size [4]. However, this technique tends to smoothen the discontinuities and thus makes the study of the cracks harder, as shown in Figure 2.

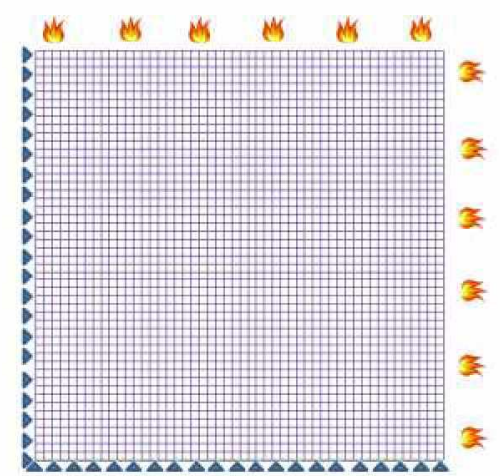

FE model

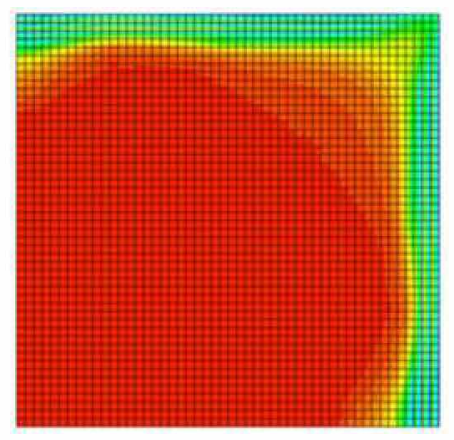

non-local technique
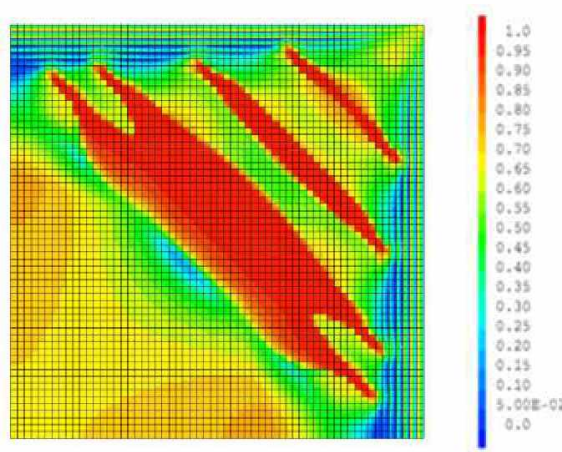

Hillerborg approach

Figure 2. Damage comparison between two regularization techniques used 
In order to evaluate the quality of identification and the pertinence of the model, a 3D Finite Element model is developed under computer code CAST3M, and is validated against the fire tests carried out within the framework of the thesis of Miah [7]. An example of modelling for a concrete slab subjected to ISO 834-1 fire under $1.5 \mathrm{MPa}$ biaxial compressive loading is given in terms of vertical displacement versus time with respect to both nonlocal technique and Hillerborg approach, as shown in Figure 3. The comparison of the experimental curve with the adapted model using Hillerborg approach appears to be in good agreement. The remaining difference between predicted with Hillerborg approach and measured displacement can be explained by the reduction of thickness due to spalling which has not been considered in the model.
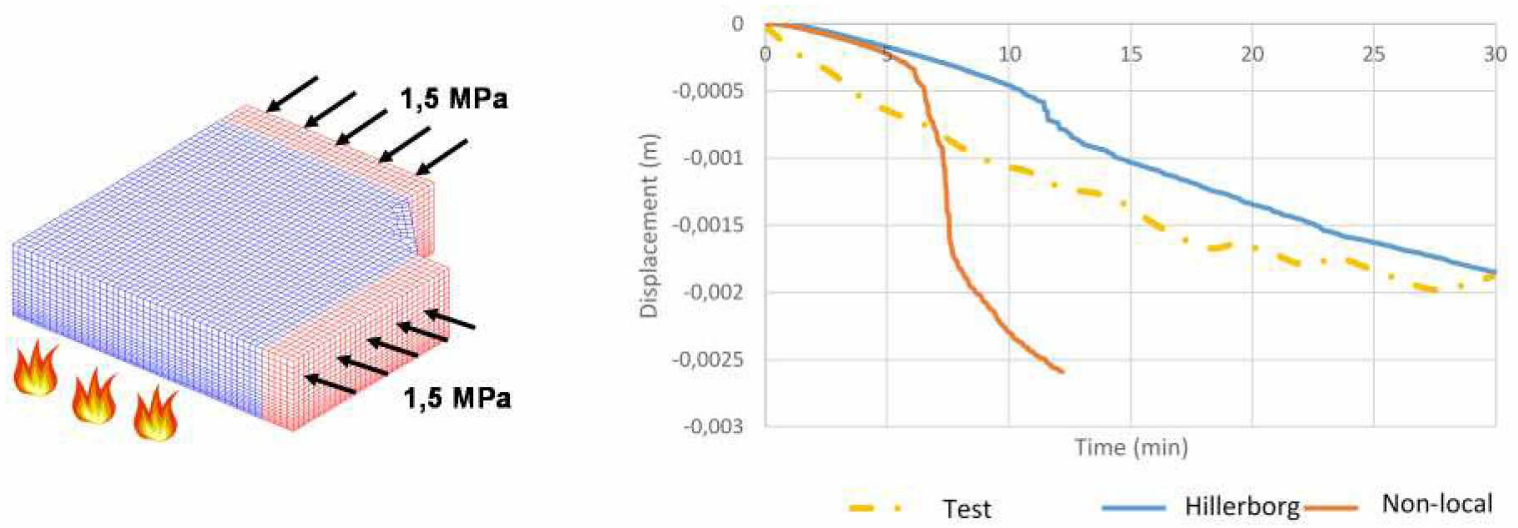

Figure 3. Detail of the structural modelling (left) and comparison between predicted and experimentally measured out of plane displacement (right)

\subsection{Heat transfer analysis}

In the heat transfer analysis, the heating of all of the walls was predicted with help of a 2D model using the cross section of the walls. Their thermal properties are those given in EN 1992-1-2 [10].

On the exposed side of the walls the net heat flux is based on heat transfer by convection and radiation. The coefficient of heat transfer by convection on the exposed face is taken as $\alpha_{C}=25 \mathrm{~W} / \mathrm{m}^{2} \mathrm{~K}$ according to EN 1991-1-2 [11] for a member exposed to the standard temperature -time curve.

A comparison of calculated temperatures with test temperatures for different distance from exposed face in cross section through the walls is illustrated in Figure 4.

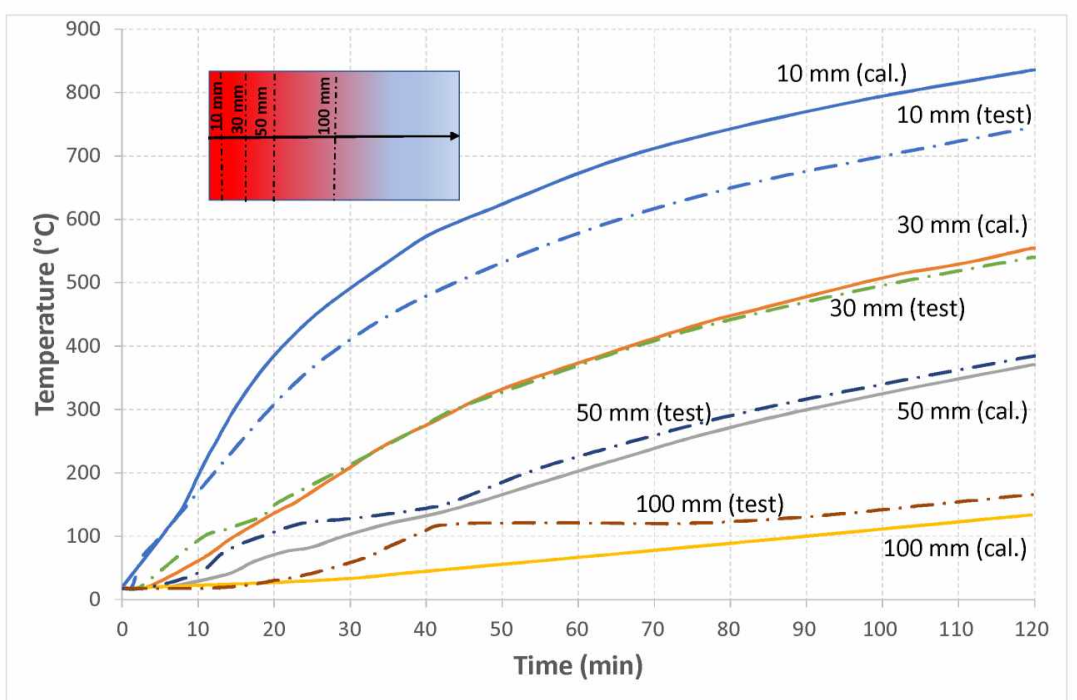

Figure 4. Comparison between numerical and experimental temperatures of the studied walls 
From this comparison, a good agreement between test and numerical modelling is evidenced, which constitutes also a good basis for mechanical analysis.

\subsection{Mechanical behaviour of the walls}

The structural analysis is based on a structural model that takes into account concrete wall and reinforcing steel mesh (Figure 5).

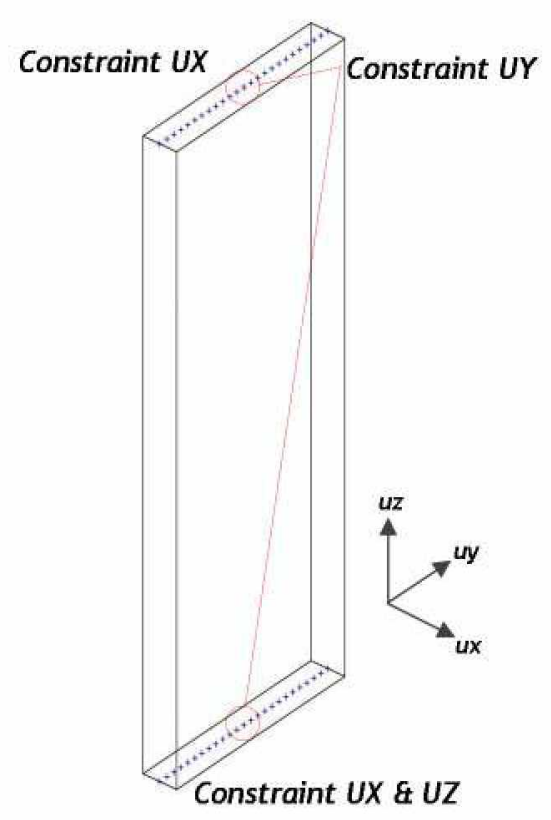

a) Boundary conditions

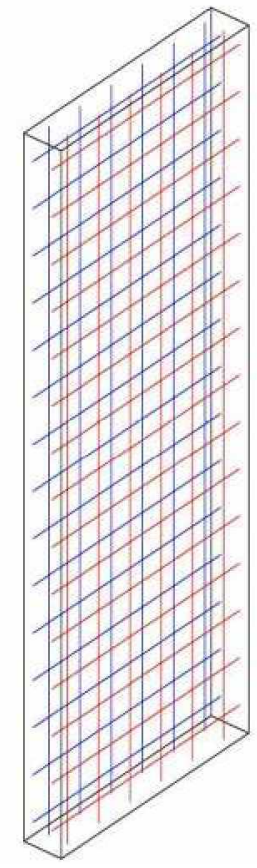

b) Reinforcement model (ST10)

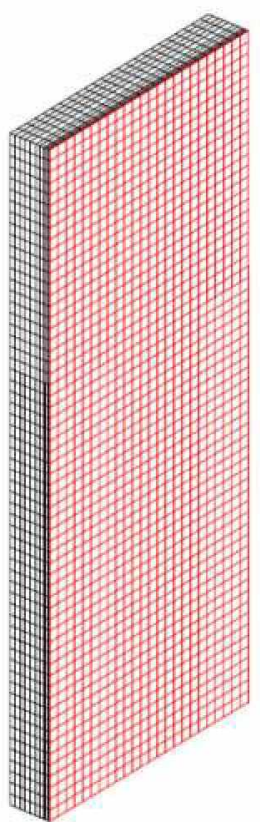

c) Concrete model

Figure 5. Detail of the structural modelling

The global structural behaviour of the walls is analysed on the basis of previously calculated temperature field. The simulated results of the walls were compared to the experimentally measured deflection by the ratio of deflection (w) to maximal experimentally measured deflection of the walls ( $W_{\text {max,test }}$ ), versus time, as shown in Figure 6. It can be observed that globally the numerical simulations follow quite closely the experimental results, except for the wall loaded at $1100 \mathrm{kN}$ in which the difference between predicted and measured displacement appears significant. This behaviour can be explained by the fact that the elaborated model does not take into account transient thermal strain, observed in the experiments where the concrete is submitted simultaneously to mechanical and thermal loads, which has an influence on the structural response. As a consequence, the wall loaded at $1100 \mathrm{kN}$ induces more transient thermal strain which leads to lower thermal expansion than the other walls, thus creating a lower thermal curvature. Moreover, it can be seen that the predicted deflections using Hillerborg approach are generally in good agreement with the experimentally measured deflection. However, this observation is not confirmed with the measured lower deflection of the wall loaded at $1100 \mathrm{kN}$. 


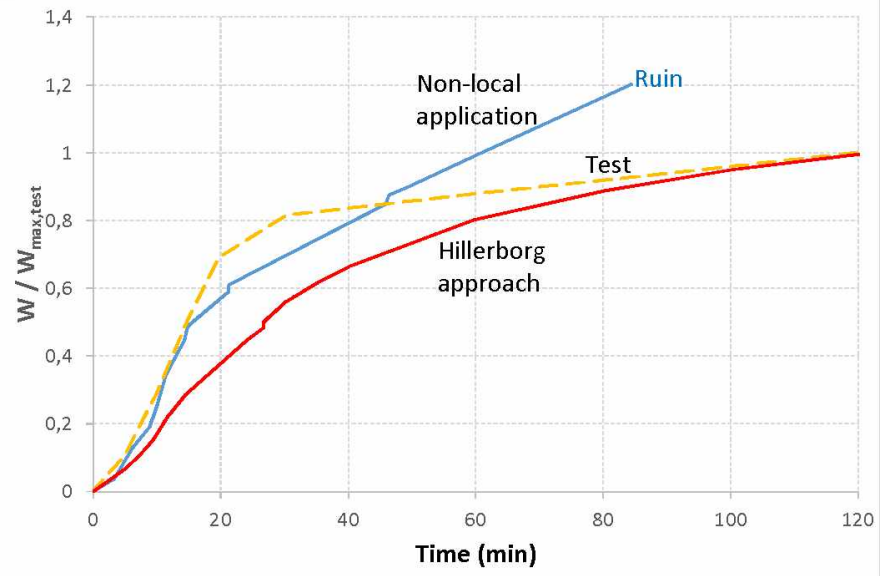

$\mathrm{F}=0 \mathrm{kN}$

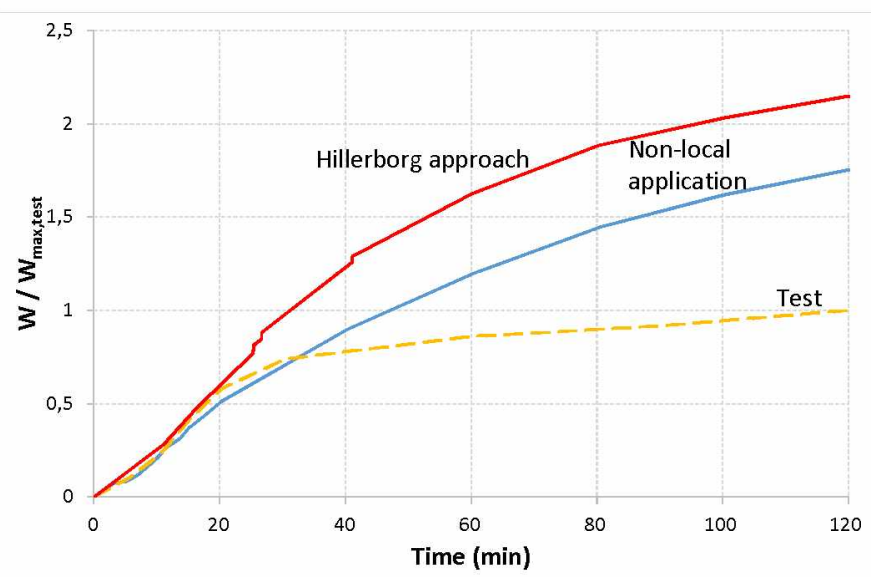

$\mathrm{F}=1100 \mathrm{kN}$

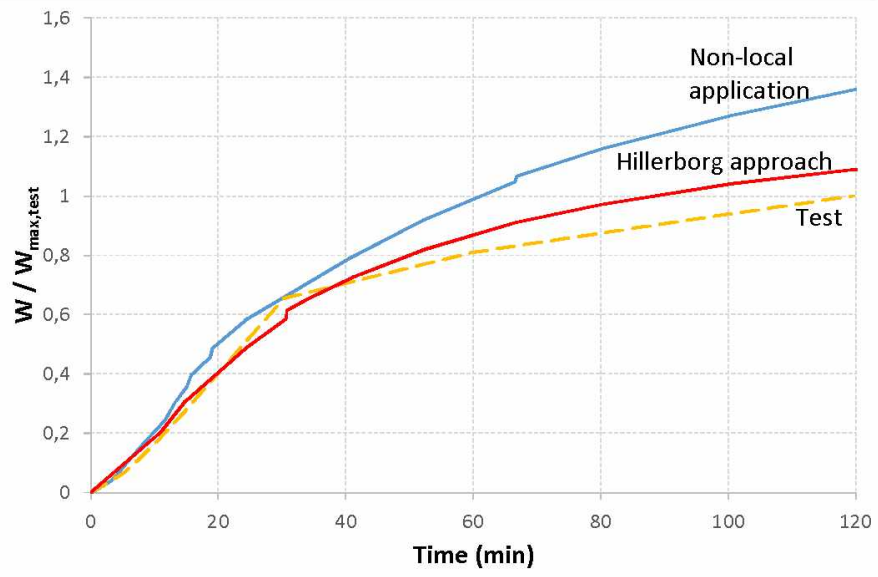

$\mathrm{F}=100 \mathrm{kN}$

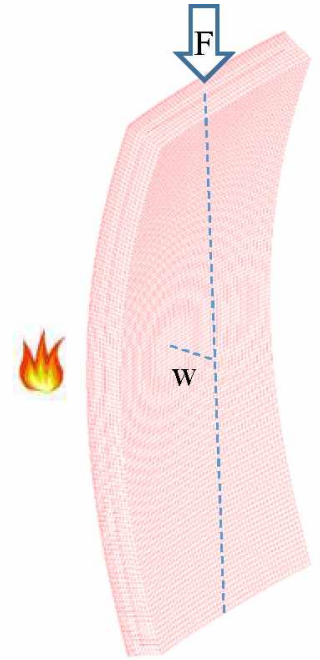

Figure 6. Comparison between numerical and experimental measured deflections, w, of the 3 walls loaded at 0,100 and $1100 \mathrm{kN}$

Figure 7 displays maps of damage in transverse section at the mid-height of the wall loaded at $100 \mathrm{kN}$ determined from calculations run using Hillerborg approach at 5, 15, 30 et 120 minutes of fire exposure. These results are in good agreement with the results reported in the literature. Indeed, the reason that concrete damage occurs near the exposed surface is due to the stress redistribution through the wall thickness. This behaviour is mainly explained by the differential thermal dilatation and that of the loss of stiffness, caused by the temperature gradient through the thickness of the wall. At the beginning of the analysis, the concrete inside the wall is cold so a tensile load is applied by the exposed surface. At this time the compressive stress is therefore increasing in the exposed surface and decreasing in the middle, becoming tensile stresses; the compressive stress increases in the hot and cold surfaces with the increasing applied compressive loading. 

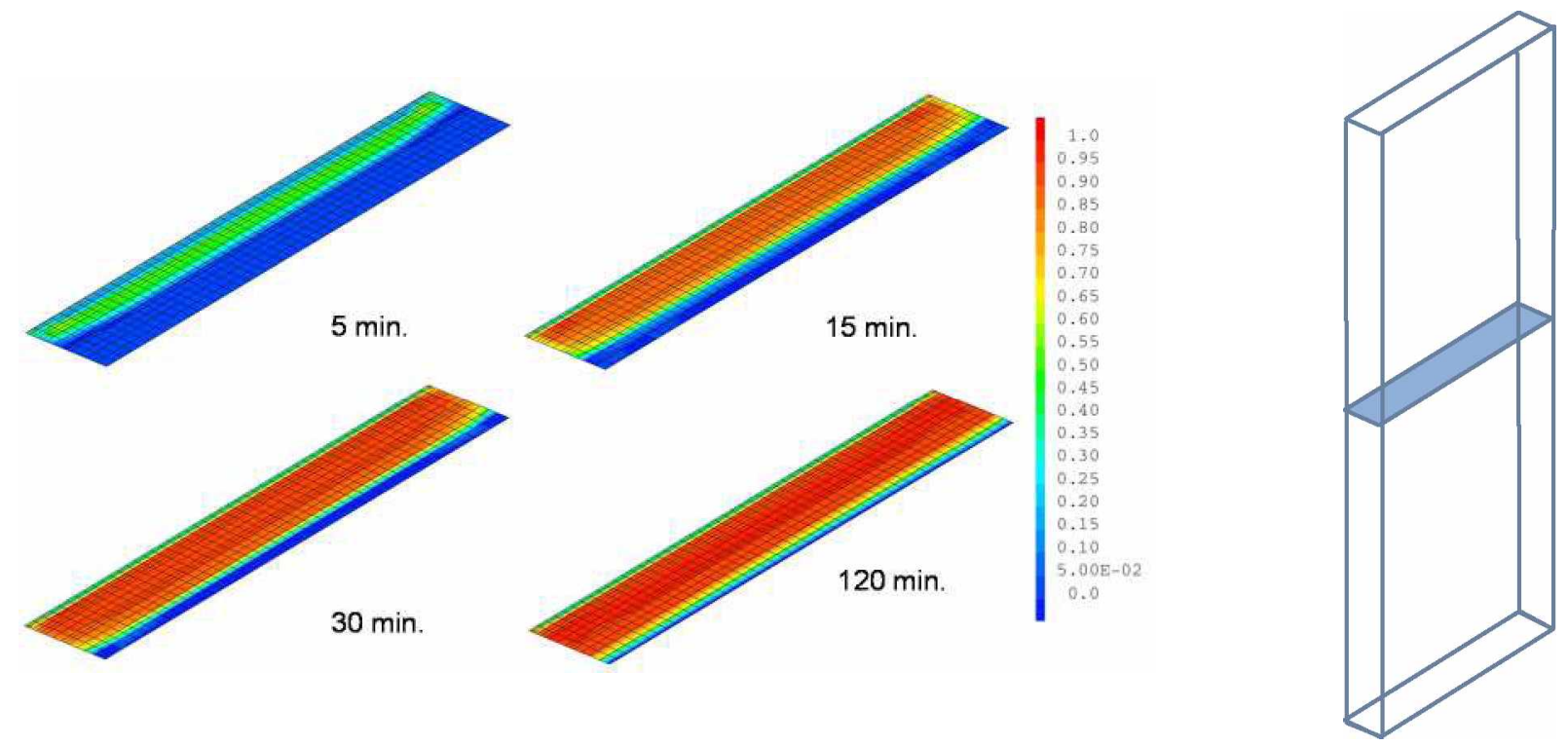

Figure 7. Distribution of the modelled damage in transverse section at the mid-height of the wall loaded at $100 \mathrm{kN}$

\section{CONCLUSIONS}

Numerical simulations of fire behaviour of reinforced concrete bearing walls demonstrate that the Mazars' elastic damageable model can be relevant for predicting the global structural behaviour of reinforced concrete structures exposed to fire but thermo-mechanical modelling of concrete has to take into account transient thermal strain. These improvements are currently undertaken by adding a new parameter in the thermo-mechanical behaviour law.

However, the local behaviour such as deshydration processes and strain incompatibility effects between cement paste and aggregates cannot be taken into account in an accurate way. In consequence, the numerical simulations would need to be adapted when such type of conditions have a significant contribution to the global structure behaviour.

\section{REFERENCES}

1. Mazars, J., Application de la mécanique de l'endommagement au comportement non linéaire et à la rupture du béton de structure, PhD Thesis. Univ. Paris 6, ENS Cachan. France, 1984.

2. Verpeaux P., Charras T. and Millard A., CASTEM 2000 : une approche moderne du calcul des structures, Calcul des Structures et Intelligence Artificielle, ed. par Fouet J-M., Ladevèze P. et Ohayon R, Pluralis, 1988, pp. 261-271.

3. Mindeguia, J. C., Contribution Expérimental a la Compréhension des risqué d'Instabilité Thermiques des Béton, PhD Thesis, Université de Pau et des Pays de l'Adour, France, 2009.

4. Bazant, Z. P. and Oh, B. H., Crack band theory for fracture of concrete, Materials and Structures, Vol. 16, 1983, pp. 155-177.

5. La Borderie, C., Stratégies et modèles de calculs pour les structures en béton, HDR Thesis, Université de Pau et des pays de l'Adour, France, 2003.

6. Bamonte, P., Felicetti, R., Kalaba, N., and Monte, F., Modelling the structural behaviour of R/C walls exposed to fire, 2016.

7. Jihad, M., M., The Effect of Compressive Loading and Cement Type on the Fire Spalling Behaviour of Concrete, PhD Thesis, Université de Pau et des pays de l'Adour, France, 2017.

8. Jihad, M., M., Pinoteau N. and Pimienta. P, A thermomechanical experimental investigation on 3 loaded concrete walls exposed to ISO 834-1 fire, 2019. 
9. Kachanov, M., Effective elastic properties of cracked solid: critical review of some basic concepts. Applied Mechanics Reviews 45, 304-335. 1959.

10. CEN, EN 1992-1-2, Eurocode 2: Design of concrete structures, Part 1-2: General rules - structural fire design, European Committee for Standardisation, 2005.

11. CEN, EN 1991-1-2, Eurocode 1: Actions on structures, Part 1-2: General actions - Actions on structures exposed to fire, European Committee for Standardisation, 2003. 